\title{
Limpet Patella spp. consumption by oystercatchers Haematopus ostralegus: a preference for solitary prey items
}

\author{
Ross A. Coleman ${ }^{1 *}$, John D. Goss-Custard ${ }^{2}$, Sarah E. A. Le V. dit Durell², \\ Stephen J. Hawkins ${ }^{1}$
}

'School of Biological Sciences, University of Southampton, Bassett Crescent East, Southampton SO16 7PX, United Kingdom ${ }^{2}$ ITE Furzebrook Research Station, Wareham, Dorset BH20 5AS, United Kingdom

\begin{abstract}
Patellid limpets are very important grazers on NE Atlantic rocky shores, and can occur in clumps or as solitary individuals. When oystercatchers are foraging for limpets on rocky shores, they are often presented with a choice between solitary and clumped limpets. We attempted to establish whether oystercatchers express a preference for limpet prey items from these different distributions. Oystercatchers spent far more time foraging in areas of less clumped limpets than in areas of clumped limpets, despite lower prey density. We found a strong preference for solitary prey items, and increased chances of successful predation of solitary limpets. Possible explanations for this choice are discussed. This preference for attacking solitary limpets may have important implications for rocky shore dynamics by shaping the spatial patterns of limpets. This may then influence the probability of Fucus germlings escaping limpet grazing.
\end{abstract}

KEY WORDS: Haematopus ostralegus $\cdot$ Patella $\cdot$ Behaviour $\cdot$ Clumping $\cdot$ Predation $\cdot$ Rocky shores

\section{INTRODUCTION}

The subject of animals living in groups has been extensively explored in the context of predation avoidance in terrestrial vertebrates (e.g. Waterman 1997), and insects (e.g. Hassell 1978). In aquatic organisms, much attention has been given to fish shoaling behaviour (e.g. Rangeley \& Kramer 1998). In this study we focus on the possible defensive role of clumping in intertidal patellid limpets as a means of reducing predation risk from oystercatchers. The consequences of such behaviour may have important implications for the community structure of rocky shores.

Previous work on grouping behaviour in intertidal molluscs has suggested aggregation to reduce the risks of dislodgment and desiccation (see Chapman \& Underwood 1992, Raffaelli \& Hawkins 1996 for review). The potential role of predation avoidance has largely been ignored in the case of large mobile pre-

\footnotetext{
•E-mail: r.coleman@soton.ac.uk
}

dators. Limpets can occur in a variety of spatial distributions from tight clumps to scattered, solitary individuals (Hartnoll \& Hawkins 1985). This behaviour has been attributed to a variety of causes (Hawkins et al. 1992), but there have been few attempts to experimentally explain these patterns. Limpets have a variety of means of defence against predation, including large size (Frank 1982, Marsh 1987, Bosman et al. 1989, Wootton 1992) and crypsis. Crypsis may occur through the growth of epizootic foliose algae on the shells of limpets (Bosman et al. 1989) or changes in shell colouration, making visual detection by predators more difficult (Sorensen \& Lindberg 1991). In work to date, the most successful means of predation avoidance by limpets is to utilise substrates inaccessible to predators (Lewis \& Bowman 1975, Frank 1982, Wootton 1992).

Although European oystercatchers Haematopus ostralegus L. are best known as predators of mussels and other estuarine bivalves (e.g. Goss-Custard \& Sutherland 1984, Evans 1988, Durell et al. 1993), they are also significant predators of limpets (Harris 1965, 
Lewis \& Bowman 1975). However, in contrast to oystercatchers preying on mussels (e.g. Harris 1965, 1967 , Goss-Custard \& Sutherland 1984, see papers in GossCustard 1996), the feeding behaviour of $H$. ostralegus on limpets has not been studied in detail in Europe. Elsewhere, limpet predation by oystercatchers has received more attention, notably in South Africa (e.g. H. moquini, Bosman et al. 1989) and on the northwest coasts of North America (e.g. H. bachmani, Frank 1982, Marsh 1987, Wootton 1992, 1993). Predation on limpets by oystercatchers has been shown to alter the population structure of limpets in terms of age structure (Lewis \& Bowman 1975, Frank 1982), size (Bosman et al. 1989), and species composition (Wootton 1992). There is also a direct community effect of limpet predation by birds since this causes an increase in macro-algal abundance by removal of a major herbivore (Wootton 1992). Reduction of limpet abundance due to birds can alter substrate availability to settling larvae, thereby indirectly affecting the outcome of interactions with acorn barnacles (Wootton 1993) and mussels (Lewis \& Bowman 1975).

The overall aim of this study was to see if oystercatchers showed any preference for solitary or clumped limpets. Since little work has been published on oystercatchers preying on limpets in NW Europe, it was also necessary to gather basic information on feeding behaviour (e.g. point of attack on limpet shells), prey species preferences (Patella vulgata, $P$. depressa or $P$. aspera), and the influence of environmental conditions on oystercatcher foraging behaviour. The study area also had to be characterized, including the abundance and distribution of limpet species present.

\section{METHODS}

Site description. This study was carried out on a rock ledge ('the flats') in Kimmeridge Bay, Dorset, UK $\left(50^{\circ} 32^{\prime} \mathrm{N}, 02^{\circ} 10^{\prime} \mathrm{W}\right.$, grid reference SY904792 SY905793). This bay has extensive areas of flat dolomite rock ledges with populations of Patella vulgata L., P. depressa Pennant and P. aspera Röding (syn. $P$. ulyssiponensis Gmëlin). The area between Poole Bay and Lulworth Cove (Dorset, UK) supports a population of wintering adult oystercatchers and nonmigratory sub-adults, which remain over summer ( $R$. Coleman pers. obs.). These oystercatchers frequently forage on limpets in Kimmeridge Bay.

Site characterization. The ledge was initially surveyed to establish the sizes of the study areas. The beach survey extended up to $1.3 \mathrm{~m}$ above chart datum, as preliminary observations had revealed that oystercatchers very rarely feed above this level in Kimmeridge Bay. Subsequently, the overall distribution and density (numbers of individuals) of limpets on the beach was determined from 130 randomly placed $0.25 \mathrm{~m}^{2}$ quadrats. In the first 50 of these quadrats, the size and species of each limpet was recorded. The extent of limpet aggregation (clumping) was shown by determining the negative binomial index $k_{i}$ small values of $k$ indicate contagion, whereas large values of $k(>8)$ indicate that the population is near randomly dispersed (Southwood 1978). Patterns of aggregation appeared to vary across the ledge. So the sampling programme was stratified, by dividing the ledge into areas of apparently similar degrees of aggregation. Each area was then measured, the density of limpets ascertained by 50 random $0.25 \mathrm{~m}^{2}$ quadrats, and the extent of contagion established by calculation of Pielou's $I_{\alpha}$ from random point to nearest neighbour individual distances (Pielou 1969, Southwood 1978). This index was used for this more detailed survey since it is not dependent on quadrat size (Pielou 1969); if the value is greater than 1, the population is contagious. The degree of clumping overall on the ledge was checked again in spring by taking 75 random $0.25 \mathrm{~m}^{2}$ quadrats, and contagion assessed as above.

Since clumped limpets might have different access to grazing compared to solitary limpets, then they may differ in their energetic value to oystercatchers. All individuals from 50 random quadrats were collected, shell length measured and their ash-free dry mass (AFDM) determined. The limpets were noted as being either solitary or clumped. The flesh of each limpet was removed and then dried to constant weight at $60^{\circ} \mathrm{C}$. The dried flesh was then ashed in a muffle furnace at $550^{\circ} \mathrm{C}$ for $8 \mathrm{~h}$. The relationship of shell length to AFDM between solitary and clumped limpets was investigated by ANCOVA, and any differences in size-frequency distributions of solitary and clumped limpets by a Kolmogorov-Smirnov test

Oystercatcher observations. The different areas of the ledge with different levels of aggregation were the observation 'arenas' for oystercatcher foraging. It was possible to observe the entire ledge from a cliff-top vantage-point using a $60 \times$ telescope. This level of magnification enabled individual predation events to be observed in detail, and the observer to see specifically whether a bird attacked a limpet in a clump or a solitary limpet. The behavioural data were described in real time into a tape recorder, which was then later transcribed into a computer using 'The Observer' (Noldus Technology, Waginengen, The Netherlands) behavioural recording software for analysis. The behaviour of each bird (focal animal observation sensu Altman 1974) was described for 5 min, with observation immediately following a predation event. This approach ensured that any difference in behaviour was not due to gross differences in internal satiation 
(Heppleston 1968), which may occur if an observation commenced at a random time. The behaviour of the birds may then have more to do with the time from the previous meal. Individuals were studied as soon as possible after they landed in the study area. Since it is very difficult to recognize individual birds returning to the ledge, incoming birds were treated as independent. The number of focal animal observations in a day depended on how many birds were on site at that time, as each bird was observed once. After an observation session, as many shells as possible were recovered from the 'arena' in which the birds had been observed. Oystercatchers were often dispersed by human activity and this provided an opportunity to collect shells from observed predation events. Since oystercatchers leave shells inverted and also since there is very little barnacle cover at Kimmeridge, it was possible to recover almost all the shells from predation events, and match them to particular birds and events. The concern of Ens (1982) that shell collection underestimates the proportion of small prey taken is not valid here due to the ease and immediacy of collection. Collected shells were identified to species, and then height, width and length were measured. Additionally, shells were analysed for direction of attack (in relation to the anterior end) where attack damage was visible. Oystercatchers virtually always carried limpets a short distance before consuming them, so shell length could be compared with the length of oystercatcher bills (Hockey 1996). These estimates of prey shell size were calibrated by collecting estimated shells (whenever possible), and measuring them in the laboratory. Limpet composition of oystercatcher diet was compared against the results of the initial survey; sizefrequency differences were checked using a Kolmogorov-Smirnov test and differences in limpet species between diet and shore assemblage were assessed using a G-test (adjusted by Williams's correction) (Sokal \& Rohlf 1995). Oystercatcher observations were taken from December 1996 to March 1997.

The following environmental parameters were recorded concurrently to the foraging observations: time of day, shade temperature using a thermometer, windspeed and direction from local meteorology records, time from previous low tide, rain (as an $0 / 1$ variable) and frost $(0 / 1)$.

Broad-scale patterns of oystercatcher foraging: Since areas of ledge with more clumped limpets would have a higher prey density, it would be expected that oystercatchers would spend more time foraging in these areas.

(1) The amount of time each bird spent in areas of each type of distribution: This was compared to an expected time spent in each type of distribution based on prey density, i.e. if $75 \%$ of the prey is in areas of clumped limpets, then the birds should spend $75 \%$ of their time foraging in these areas. The difference between observed and expected times spent in different distributions was examined by a $\chi^{2}$ test.

(2) Rate of movement (number of paces per second): Because of the difference in prey densities, we expected there to be different pace rates in areas of clumped and solitary limpets. Pace rates were defined as the number of steps per second in each area, and only referred to time spent moving around the ledge, in between attacks and handling limpets. Steps taken whilst attacking or consuming a limpet were not included. Pace rates were also recorded in Fucus patches, in rock pools or on areas of unknown substrate (visibility obscured). Pace rates between different areas were assessed by means of a 1-way ANOVA.

Attack preferences: (1) Target prey: This recorded the number of prey items attacked from different distributions (clumped or solitary limpets, or unknown if visibility was obscured) per bird in a $5 \mathrm{~min}$ period. Observations of attacks were described independently of the areas noted above; a bird may be in an area of more dispersed limpets and attack a clumped limpet or vice versa. Any attacks were observed directly. These observations included both successful and unsuccessful attacks. The number of observed attacks were checked for heterogeneity of variances and then log transformed to remove such heterogeneity (Underwood 1997), and mean numbers of attacks on limpets from different distributions analysed by a Student's $t$-test. The size distribution of limpets in the diet was compared to the size frequency of limpets measured in the preliminary survey by a Kolmogorov-Smirnov test. The number of limpets of each species in the diet was compared with the number of each species on the ledge (from the preliminary survey) by a $G$-test adjusted by Williams's correction (Sokal \& Rohlf 1995).

(2) Pecks per limpet: Limpets in clumps may require different amounts of force to remove than solitary limpets; so they may require more or less pecks to remove than solitary limpets. So for each attack on an individual limpet, the number of pecks per second was noted. Attacks within Fucus beds were not included in the analysis since it was impossible to see exactly what the birds were attacking. Pecking at limpets can be either single 'probe' pecks or repeated pecks. The mean duration of probe pecks (time from start of peck to start of next activity, in seconds) between solitary and clumped limpets was analysed by a Student's $t$-test. The difference in mean peck rates number of pecks on an individual limpet per second) of attacks on solitary and clumped limpets was tested using a Student's $t$-test on log transformed data.

(3) Proportion of attacks that were successful, and giving-up time: Not all pecks result in a limpet being 
dislodged. If an attack was unsuccessful, the amount of time birds spent (giving-up time) was assessed by odds ratio $\omega$ (Sokal \& Rohlf 1995), which is used to evaluate differences in proportions. In this test, $\omega$ was the ratio of probabilities of attacks on solitary limpets being greater or less than the median for all attacks divided by the ratio of probabilities of attacks on clumped limpets being than greater or less than the median. The deviation of $\omega$ from the null case of 1 was tested using a G-test adjusted by Williams's correction (SokaI \& Rohlf 1995). The chance of an attack being successful on clumped or solitary limpets, or unsuccessful on either, was evaluated by $\omega$.

\section{RESULTS}

\section{Site characterization}

On the ledge overall, the density of limpets was $10.5 \mathrm{~m}^{-2}(\mathrm{n}=130, \mathrm{SE}=0.68)$ in winter and $12.2 \mathrm{~m}^{-2}$ $(\mathrm{n}=75, \mathrm{SE}=1.06)$ in spring, the difference was not significant $\left(t_{203}=1.048, n s\right)$. Overall on the ledge, the limpet population was clumped $(k=0.46)$ in December 1996, but decreased in time (in March 1997, $k=0.83$ ). The stratified sampling programme confirmed different levels of aggregation on the ledge. There were 5 distinct areas, comprising 3 patches of relatively low levels of clumping (i.e. more dispersed) (approx. $675 \mathrm{~m}^{2}$ in total) compared to the other 2 areas (approx. $675 \mathrm{~m}^{2}$ in total), with higher values of $I_{\alpha}$ where limpets were more clumped, where the density of limpets approximately doubled that of the more dispersed areas (Table 1). These areas are shown on Fig. 1. Solitary and clumped limpets did not differ in their energy value to oystercatchers. Slopes of $\log _{10}$ AFDM against log length for solitary and clumped limpets were not significantly different (ANCOVA; $F_{(6,192)}=0.41$, ns) (Fig. 2), and the size-frequency distributions of clumped and solitary limpets did not differ (Kolmogorov-Smirnov test, $D_{(56,138)}=1.124, \mathrm{~ns}$ )

Table 1 Areas of the patches and densities of limpets. The areas of the 3 Fucus beds have been combined for a single value. Pielou's $I_{\alpha}$ is a random point to nearest-neighbour measure of dispersion (Pielou 1969, Southwood 1978), 1 is random, < 1 regular and $>1$ aggregated

\begin{tabular}{|lcccl|}
\hline Patch & $\begin{array}{c}\text { Area } \\
\left(\begin{array}{c}\text { approx. }) \\
\left(\mathrm{m}^{2}\right)\end{array}\right.\end{array}$ & $\begin{array}{c}\left.\text { Limpet density (ind. } \mathrm{m}^{-2}\right) \\
(\text { mean of twenty } \\
\left.0.25 \mathrm{~m}^{2} \text { quadrats }\right)\end{array}$ & $\begin{array}{c}\text { Pielou's } \\
I_{\alpha}\end{array}$ & Comments \\
\hline 1 & 275 & 6.51 & 1.10 & More dispersed \\
2 & 100 & 1.43 & 1.162 & More dispersed \\
3 & 225 & 15.02 & 1.46 & More aggregated \\
4 & 300 & 5.41 & 1.26 & More dispersed \\
5 & 450 & 15.02 & 1.66 & More aggregated \\
Fucus & 430 & Not measured & na & Fucus \\
\hline
\end{tabular}

Kimmeridge Bay

Study Area (SY904792-SY905793)

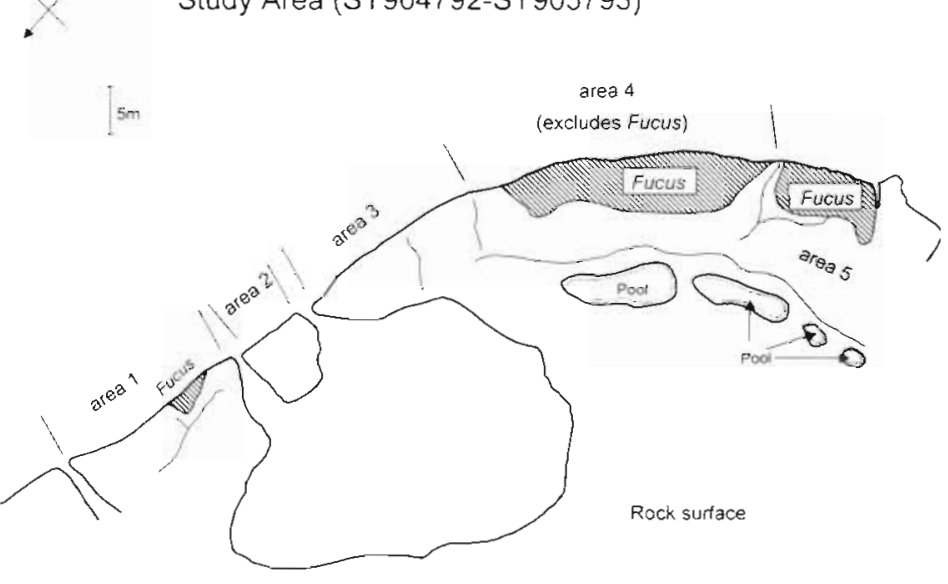

Fig. 1. Study area in Kimmeridge Bay, Dorset, UK. The rock is shown to the level of mean low water (MLW). Fucus beds are shown shaded

\section{Oystercatcher observations}

Broad-scale patterns of oystercatcher foraging

Thirty-one 5 min observations of birds feeding on the site were taken, with a maximum of 6 birds feeding at any one time. Human pressure was higher than anticipated, so the birds were often disturbed.

(1) Time per distribution: Oystercatchers spent significantly more time foraging in the areas of more dispersed limpets compared to times in areas of more aggregated limpets than would be expected on the basis of different prey densities $\left(\chi^{2}=214.55,1 \mathrm{df}\right.$, $p<0.001$ ) (Fig. 3) or compared to the expected times based on the relative areas of each distribution $\left(\chi^{2}=99.40,1 \mathrm{df}, \mathrm{p}<0.001\right)$. Some birds foraged in Fucus beds, the observed time spent foraging in Fucus (mean 69.5 s) was identical to that expected (73 s) based on relative area of Fucus beds. The birds did not stay consistently in one area, but changed areas more frequently according to the number of birds on the site (positive effect) and temperature (inverse effect) (hierarchical log linear analysis, reduction in $G=57,49,75 \mathrm{df}$, $\mathrm{p}<0.02)$.

(2) Rate of movement: The oystercatchers showed no difference in pace rates within areas of different limpet distribution (mean pace rate in solitary limpets was 104.4 paces $\mathrm{s}^{-1}$, SE 7.95; in more aggregated limpets mean pace rate was 99.1 paces $s^{-1}$, SE $8.30 ; 1$-way ANOVA, $\left.F_{(4,49)}=1.96, \mathrm{~ns}\right)$. 


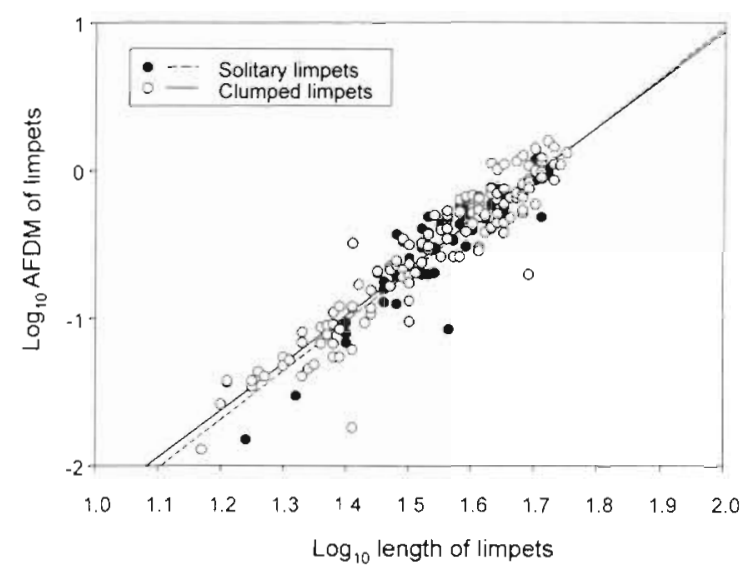

Fig. 2. Relationship between log shell length and log ash-free dry mass (AFDM) of solitary and clumped limpets from Kimmeridge taken from 50 random quadrats. Each datum point represents 1 limpet. Two regression lines are shown: (--) regression for solitary limpets $(\log \mathrm{AFDM}=2.68 \mathrm{log}$ shell length $\left.-4.63 ; \mathrm{r}^{2}=0.614 ; F_{(1.29)}=17.56, \mathrm{p}<0.001\right)$, and $(-)$ regression for clumped limpets (log AFDM $=3.358$ log shell length $-5.65 ; \mathrm{r}^{2}=0.894 ; F_{(1,58)}=230.87, \mathrm{p}<0.001$ ) These regressions were not significantly different in either slope (ANCOVA; $F_{[6,192)}=0.41$, ns) or intercept $\left(\mathrm{ANCOVA}_{\mathrm{i}}\right.$ $\left.F_{(1,192)}=0.68, \mathrm{~ns}\right)$

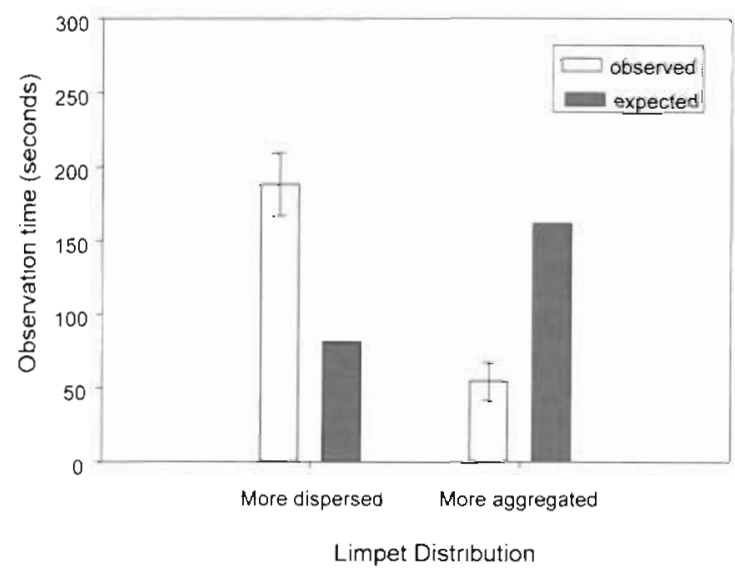

Fig. 3. Mean amount of time oystercatchers spent in patches of different prey distribution compared to expected times based on random foraging according to prey density in the areas of more aggregated and more dispersed limpets. The expected and observed times differed significantly $\left(\chi^{2}=214.6,2 \mathrm{df}, \mathrm{p}<0.001\right)$. Based on observations of 31 birds of $5 \mathrm{~min}(300 \mathrm{~s})$ duration

\section{Attack preferences}

(1) Target prey: Oystercatchers showed a significant preference for attacking solitary limpets (log transformed number of attacks, $t_{38}=2.57, p<0.05$ ); solitary limpets were attacked approximately 2.5 times more often than clumped limpets (Fig. 4). There was a strong preference for attacking the anterior end of the limpet, irrespective of species (Fig. 5). The frequency distribution of sizes of limpets taken as prey was not different from that of available prey (Kolmogorov-Smirnov, $D_{(42,92)}=0.578$, ns) (see Fig. 6). Limpet species composition of oystercatcher diet was significantly different from that of the limpet assemblage on the shore $\left(G_{a d j}=6.61,2 \mathrm{df}, \mathrm{p}<0.05\right)$, with more Patella aspera being taken than would be expected (Fig. 7).

(2) Pecks per limpet: Pecking at limpets was of 2 types: single probe pecks and more prolonged repeated pecks. The mean duration of a probe peck was not different between attacks on solitary (0.94 s, $\mathrm{n}=390, \mathrm{SE} 0.02)$ or clumped limpets $(0.61 \mathrm{~s}, \mathrm{n}=94, \mathrm{SE}=0.04)\left(t_{482}=0.598\right.$, ns). Repeated pecking at solitary limpets was found to be approximately $20 \%$ faster than pecking at clumped limpets: mean peck rate on solitary limpets $=2.17$ pecks $\mathrm{s}^{-1}$ and mean peck rate on clumped limpets $=1.78$ pecks $\mathrm{s}^{-1}$. This difference was significant $\left(\log _{10}\right.$ mean solitary $=$ $0.26, \mathrm{n}=158, \mathrm{SE}=0.021 ; \log _{10}$ mean clump $=0.19, \mathrm{n}=56$, $\mathrm{SE}=0.032 ; 1$-tailed $t_{212}=1.75, \mathrm{p}<0.05 ; \log$ transformed to remove heterogeneity of variances, Levene's test $F=$ 5.69, p<0.05).

(3) Proportion of attacks that were successful, and giving-up time: There was no difference in the odds of an oystercatcher giving up on attacks of solitary or clumped limpets in relation to the median time taken. The odds ratio $\omega$ (Sokal \& Rohlf 1995) of the amount of time that an oystercatcher spent on a prey item before giving up was 1.09 (SE 0.341), and was not different from the null case of $\omega=1\left(G=0.07, \chi_{0.05}^{2} 1 \mathrm{df}=3.841\right.$, $n s)$. The chances of an oystercatcher successfully attacking solitary limpets were twice as large as the chances of successfully attacking clumped ones $(\omega=$

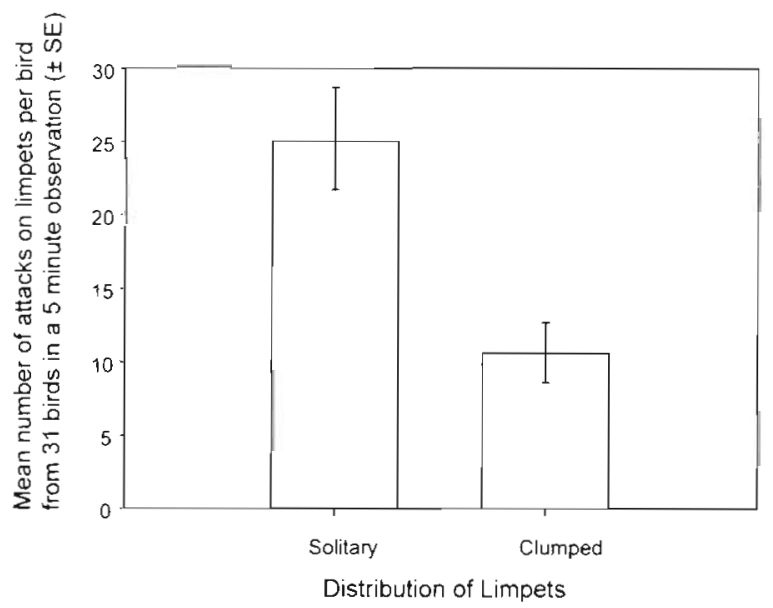

Fig. 4. Mean number of attacks on solitary or clumped limpets per $5 \mathrm{~min}$ observation period. Over the study period, 31 birds were observed feeding on limpets. The preference for solitary limpets was significant $\left(t_{38}=2.57, p<0.05, \log \right.$ transformed data) 


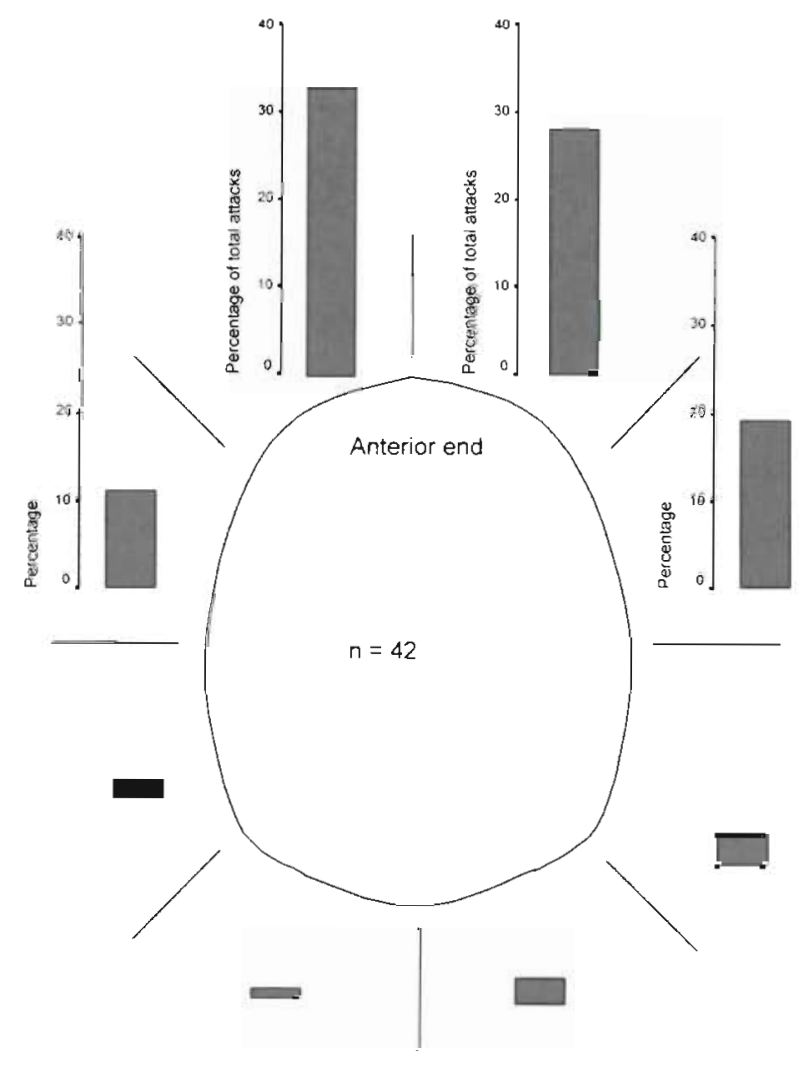

Fig. 5. Direction of attack by oystercatchers on limpet shells. This was noted from shell damage on the lip, and is shown from a dorsal view. Axes refer to percentage of total attacks for each sector; axes have been removed from bars on the lower half of the figure for clarity; these bars are drawn to the same scale

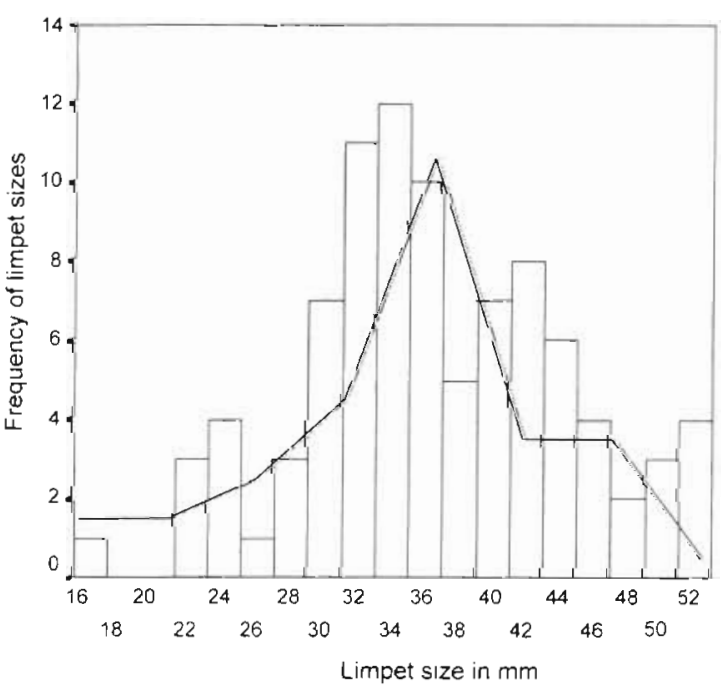

Fig. 6. Patella spp. Sizes of limpets (pooled for all species of limpet) on the study site and taken by birds. Bars: Frequency of limpet sizes on the site from 50 random $0.25 \mathrm{~m}^{2}$ quadrats; (-) frequency of limpets of different sizes taken by 31 oystercatchers from 31 observations of 5 min each

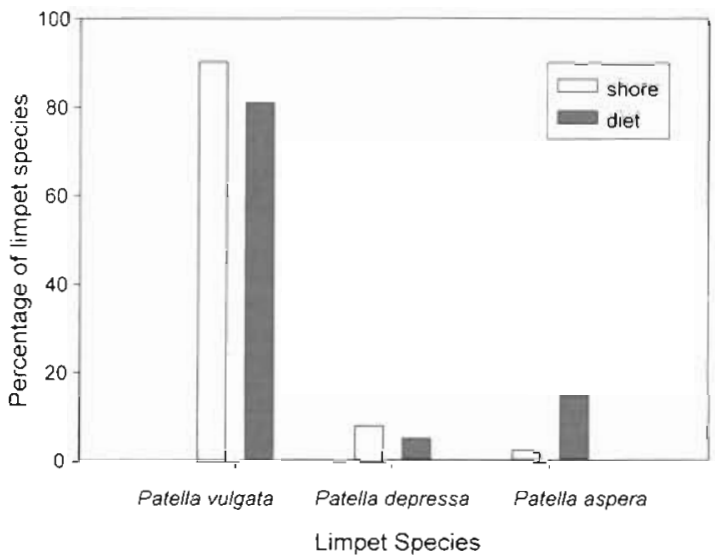

Fig. 7. Species of limpets on the site and taken by oystercatchers. Bars represent percentage frequency of limpet species on the site from 50 random $0.25 \mathrm{~m}^{2}$ quadrats, and the percentage frequency of limpets of different sizes taken by 31 oystercatchers from 31 observations of 5 min each

2.06, significantly different from $\omega=1, G=6.00,1 \mathrm{df}$ $\mathrm{p}<0.01$ ) (Fig. 8)

Variations in the duration (time taken to remove) and rate of successful attacks (number of successful attacks in $5 \mathrm{~min}$ ) were not explained by any factor (rain, temperature, distribution, frost, wind, number of birds on site or time from low water) (GLM, no factor significant, model $\left.F_{(2.85)}=2.185, \mathrm{p}<0.05\right)$. Hierarchical $\log$ linear analysis revealed that differences in numbers of prey consumed between different birds in 5 min were associated with 3 separate factors acting independently: number of birds on site (reduction in $G=15.25,15 \mathrm{df}, \mathrm{p}<0.001$ ), temperature (reduction in $G=56.75,15 \mathrm{df}, \mathrm{p}<0.001$ ), and wind strength (reduction in $G=44.49,4 \mathrm{df}, \mathrm{p}<0.05)$.

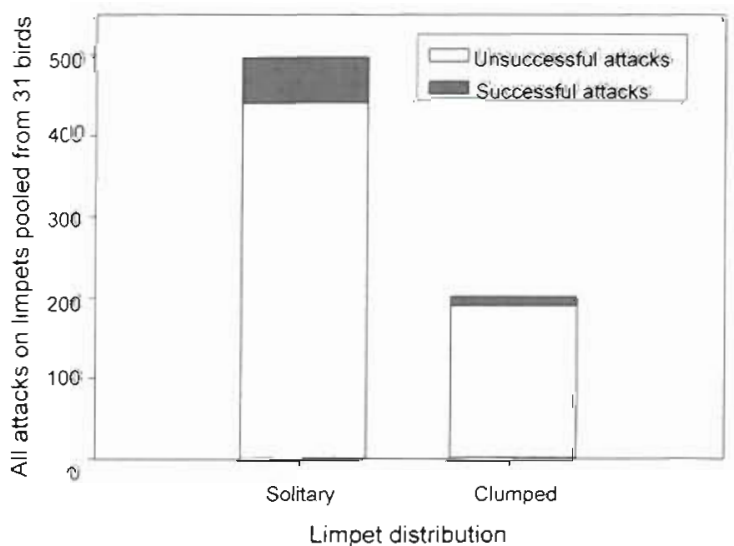

Fig. 8. All attacks on limpets from different distributions by oystercatchers pooled from 5 min observations of 31 birds. Oystercatchers were likely to be twice as successful in attacks on solitary limpets as in attacks on clumped limpets $(\omega=2.06$,

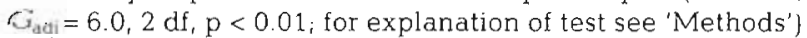




\section{DISCUSSION}

Oystercatchers attack limpets by lowering their heads, and hitting the lowest edge of the anterior part of the shell (Fig. 5) with the bill (Hulscher 1996), either displacing the limpet or twisting the limpet around on its axis. This may take several blows. Once the limpet is detached or loosened from the home scar, the bill may be inserted under the edge of the shell and the limpet flipped over. The shell contents are then removed and consumed (Feare 1971, Hulscher 1996). The single probe pecks probably serve to check the strength of prey attachment; hence the duration of these pecks does not differ between solitary and clumped limpets. Since oystercatcher giving-up times do not seem to differ between clumped and solitary prey items, it seems likely that the information gained in the probe peck, i.e. how loose a limpet is on its home scar, could be more important than distribution in the decision of whether to continue an attack already commenced.

The most important factor determining which limpets oystercatchers attacked seemed to be the distribution of the prey. The birds showed a strong preference for attacking solitary limpets, and experienced a much higher success rate attacking solitary limpets compared to clumped limpets; they also spent more time foraging in areas of more dispersed limpets. Oystercatchers pecked faster at solitary limpets, implying a greater investment of energy into attacking these as opposed to clumped limpets. The results of Feare (1971) indicating a preference for Patella aspera were borne out by our results, probably for the same reasons. At Kimmeridge, oystercatcher selection of limpet prey appeared not to be based on size. The potential energy return (as estimated by ADFM) from both solitary and clumped limpets was not different across the range of sizes, so some other attribute of solitary limpets may make them a more suitable prey item.

As it was impossible to see what the birds were attacking whilst they were foraging in Fucus beds, the contribution of prey in Fucus beds to oystercatcher diet was not tractable. However, the birds did spend the same time foraging in the Fucus beds as predicted by area alone, which suggests no avoidance or attraction to such areas. Possibly this is because the increase in search time due to foraging in Fucus is balanced by the greater ease of removing limpets. The atmosphere under Fucus will be far more humid than on bare rock, so that limpets are less likely to be clamped down, and so easier to remove.

Two possible mechanisms may be suggested to account for the preference for solitary limpets. Firstly, solitary limpets may be easier than clumped limpets for birds to strike, i.e. they may be more accessible. As oystercatchers tend to attack the anterior end of limpets (our results, and Feare 1971), then limpets in groups may be harder to attack because of their proximity to each other. This means there will be fewer favourable angles to strike the limpet. A second explanation is that clumping in limpets may represent a form of anti-predator strategy beyond a simple dilution model, where the risk to an individual prey is reduced by being surrounded by conspecifics (Krebs \& Davies 1987). When limpets are startled, they clamp down, presumably making it harder for predators to remove them. When an oystercatcher attacks a limpet, other limpets in the group may perceive the attack through vibrations and clamp down, making themselves harder to remove; this represents differences in prey availability (Sutherland 1996). If this were the case, we would expect that oystercatchers would not attack other limpets in the same clump, but move to another; in this way an oystercatcher may treat a clump of limpets as consisting of 1 possible prey item. Data to test this idea are not yet available. Due to the very rapid movement of oystercatchers across the ledge it was not possible to determine whether a bird attacked 1 limpet in a clump or more than 1. However, the impression gained was that the birds seemed to choose just 1 limpet in a clump. Furthermore, after a successful attack, oystercatchers carry limpets a short distance before consumption, this may mean that a second attack on the same clump is less likely. Although probe pecks did not differ in duration between solitary and clumped limpets, we have no measure of the force being applied by the oystercatchers. It is possible that the birds apply different levels of force in a first strike to limpets from different distributions. Thus the underlying mechanism of prey choice in oystercatchers foraging on limpets is not clear, and the above can be seen as models to develop hypotheses to be tested.

What are the wider implications of this preference for attack of solitary limpets? Clumping may represent a possible defence for limpets against oystercatcher predation. There are, however, other possible explanations. One of the most common explanations given for limpet clumping is protection from physical factors. Being in a clump may mean increased relative humidity inside the clump and a more stable microclimate when the tide is out. However, at Kimmeridge, limpet clumping is highest over winter and decreases over spring, when desiccation stress is increasing, which may indicate that other factors might be involved. Clumping may reduce risk to individuals from wave surge, which would tend to be higher in winter than spring. Other factors such as winter reproduction may be involved in winter aggregation as Patella vulgata, the dominant limpet species on the south coast of the UK, reproduces in autumn/winter (Ballantine 1961, Lewis \& Bowman 1975); so being close to others may 
increase reproductive success. Competition for food resources in spring may be responsible for increased dispersion, as it is likely that limpets in the centre of clumps have reduced access to grazing compared to 'outer' limpets. So, as metabolic rates rise with ambient temperature, an increased food intake is required, and energy maximization takes over from risk minimization. Manipulative experiments are needed to tease apart these hypotheses.

At the community level, a preference for solitary limpets may have marked effects on rocky shore community structure. By selectively removing solitary limpets, oystercatchers may create areas of very low limpet density as well as reinforcing the clumped nature of the limpet distribution. The aggregated distribution of limpets and subsequent uneven distribution of grazing may increase the probability of Fucus germlings escaping limpet grazing between limpet clumps. This therefore may contribute to both the patchiness of algae and fluctuations in limpet/algal mosaics seen on many rocky shores (e.g. Hartnoll \& Hawkins 1985, Johnson et al. 1997).

Our major aim in undertaking this study was to evaluate any oystercatcher preference for prey from different spatial distributions. A preference for solitary limpets was clearly shown by the results of direct observations. No previous study has demonstrated a preference by oystercatchers for limpets from different distributions; hence this study adds a new dimension to the work on bird predation on rocky shores, and may have implications for community dynamics.

Acknowledgements. We would like to thank Peter Tinsley and the Dorset Trust for Nature Conservation, and Major J. C. Mansell of Smedmore Estates for allowing us access to Kimmeridge Bay. Ray Cornick assisted with both fieldwork and graphics. This work was supported by an NERC grant GR9/2762 to S.J.H. and J.D.G.C., with additional support to R.A.C. and S.J.H. from the EU under MAST programme contract number MAS3-CT95-0012 (EUROROCK).

\section{LITERATURE CITED}

Altman $J$ (1974) Observational study of behaviour: sampling methods. Anim Behav 49:227-267

Ballantine WJ (1961) The population dynamics of Patella vulgata and other limpets. PhD thesis, Queen Mary's College, University of London

Bosman AL, Hockey PAR, Underhill LG (1989) Oystercatcher predation and limpet mortality: the importance of refuges in enhancing the reproductive output of prey populations. Veliger 32:120-129

Chapman MG, Underwood AJ (1992) Foraging behaviour of marine benthic grazers. In: John D, Hawkins SJ, Price J (eds) Plant-animal interactions in the marine benthos. Systematics Association Spec Vol 46, Clarendon Press, Oxford, p 289-317

DureIl SEA Le V dit, Goss-Custard JD, Caldow RWG (1993) Sex-related differences in diet and feeding method in the oystercatcher Haematopus ostralegus. J Anim Ecol 62 $205-215$

Ens B (1982) Size selection in mussel feeding oystercatchers Wader Stud Gr Bull 34:16-20

Evans PR (1988) Predation of intertidal fauna by shorebirds in relation to time of day, tide and year. In: Chelazzi $G$ Vannini $M$ (eds) Behavioural adaptation to intertidal life. Plenum, New York, p 65-75

Feare CJ (1971) Predation of limpets and dogwhelks by oystercatchers. Bird Study 18:121-129

Frank PW (1982) Effects of winter feeding on limpets by black oystercatchers, Haematopus bachmani. Ecology 63 1352-1362

Goss-Custard JD (ed) (1996) The oystercatcher: from indi viduals to populations. Oxford University Press, Oxford

Goss-Custard JD, Sutherland WJ (1984) Feeding specialisations in oystercatchers Haematopus ostralegus. Anim Behav 32:299-300

Harris MP (1965) The food of some Larus gulls. Ibis 107:43-54

Harris MP (1967) The biology of oystercatchers (Haematopus ostralegus) on Skokholm island, S. Wales. Ibis 109:180-193

Hartnoll RG. Hawkins SJ (1985) Patchiness and fluctuations on moderately exposed rocky shores. Ophelia 24:53-63

Hassell RMP (1978) The dynamics of arthropod predator-prey systems. Princeton University Press, Princeton

Hawkins SJ, Hartnoll RG, Kain JM, Norton TA (1992) Plant-animal interactions on hard substrata in the NorthEast Atlantic. In: John D, Hawkins SJ, Price J (eds) Plantanimal interactions in the marine benthos. Systematics Association Spec Vol 46, Clarendon Press, Oxford, p 1-32

Heppleston PB (1968) An ecological study of the oystercatcher (Haematopus ostralequs occidentalis Neumann) in coastal and inland habitats of N.E. Scotland. PhD thesis, University of Aberdeen

Hockey PAR (1996) Haematopus ostralegus in perspective: comparisons with other oystercatchers. In: Goss-Custard JD (ed) The oystercatcher: from individuals to populations. Oxford University Press, Oxford, p 251-258

Hulscher JB (1996) Food and feeding behaviour. In: GossCustard JD (ed) The oystercatcher: from individuals to populations. Oxford University Press, Oxford, p 7-29

Johnson MP, Burrows MT, Hartnoll RG, Hawkins SJ (1997) Spatial structure on moderately exposed rocky shores: patch scales and the interaction between limpets and algae. Mar Ecol Prog Ser 160:209-215

Krebs JR, Davies NB (1987) An introduction to behavioural ecology, 2nd edn. Blackwell Scientific, Oxford

Lewis JR, Bowman RS (1975) Local habitat induced variation in population dynamics of Patella vulgata L. J Exp Mar Biol Ecol 17:165-203

Marsh CP (1987) Impact of avian predators on high intertidal limpets. J Exp Mar Biol Ecol 104:185-201

Pielou EC (1969) An introduction to mathematical ecology. Wiley Interscience, New York

Raffaelli D, Hawkins SJ (1996) Intertidal ecology. Chapman and Hall, London

Rangeley RW, Kramer DW (1998) Density dependant antipredator tactics and habitat selection in juvenile pollack. Ecology 89:743-758

Sokal RR, Rohlf FJ (1995) Biometry, 3rd edn. WH Freeman, New York

Sorensen FE, Lindberg DR (1991) Preferential predation by American black oystercatchers on transitional ecophenotypes of the limpet Lottia pelta Rathke. J Exp Mar Biol Ecol 154:123-136

Southwood TRE (1978) Ecological methods, 2nd edn. Chapman and Hall, London 
Sutherland WJ (1996) From individual behaviour to population ecology. Oxford University Press, Oxford

Underwood AJ (1997) Experiments in ecology: their logical design and interpretation using analysis of variance. Cambridge University Press, Cambridge

Waterman JM (1997) Why do male Cape ground squirrels live in groups? Anim Behav 53:809-817

Editorial responsibility: Otto Kinne (Editor),

Oldendorf/Luhe, Germany
Wootton JT (1992) Indirect effects, prey susceptibility, and habitat selection. Impact of birds on limpets and algae. Ecology 73:981-991

Wootton JT (1993) Indirect effects and habitat use in an intertidal community: interaction chains and interaction modifications. Am Nat 141:71-89

Submitted: November 2, 1998; Accepted: December 21, 1998 Proofs received from author(s): June 14, 1999 